\title{
Comprehensive Geriatric Assessment
}

National Cancer Institute

\section{Source}

National Cancer Institute. Comprehensive Geriatric Assessment. NCI Thesaurus. Code C116565.

The complete examination of an elderly individual, which includes a full valuation of the physical and cog nitive conditions, as well as a check of the patient's emotional state. 